Article

\title{
Positive Relational Management for Sustainable Development: Beyond Personality Traits-The Contribution of Emotional Intelligence
}

\author{
Annamaria Di Fabio ${ }^{1, *}$ and Donald H. Saklofske ${ }^{2}$ \\ 1 Department of Education and Psychology (Psychology Section), University of Florence, Via di San Salvi, 12, \\ Complesso di San Salvi, Padiglione 26, 50135 Firenze, Italy \\ 2 Psychology Department, University of Western Ontario, London, ON N6A5C2, Canada; dsaklofs@uwo.ca \\ * Correspondence: adifabio@psico.unifi.it
}

Received: 3 September 2018; Accepted: 4 January 2019; Published: 10 January 2019

\begin{abstract}
Positive relationships are of major importance in our personal and working lives for promoting well-being, and fostering healthy and sustainable organizations. The research literature suggests that emotional intelligence is a key factor in promoting and maintaining positive relationships. We examined the association between trait emotional intelligence and positive relational management in Italian workers, controlling for the effects of personality traits. Participants were administered the Big Five Questionnaire (BFQ), the Trait Emotional Intelligence Questionnaire Short Form (TEIQue-SF) and the Positive Relational Management Scale (PRMS). Hierarchical regression analyses showed that trait emotional intelligence explained an additional $14-16 \%$ of the variance beyond personality traits in relation to positive relational management in workers. These results underscore the relationship between trait emotional intelligence and positive relational management, offering new opportunities for promoting both personal well-being and healthy and sustainable organizations.
\end{abstract}

Keywords: emotional intelligence; positive relational management; healthy organizations; healthy business; sustainability and sustainable development

\section{Introduction}

Relationships are an important need of people both in personal and working contexts [1] and are a major factor in promoting and supporting their health and well-being [2,3]. Since relationships are fundamental to the individual's personal well-being [4-6], improving positive relationships can further foster well-being in the workplace $[3,7,8]$ by promoting healthy and sustainable organizations [9-11] and increasing the adaptability of workers confronted with the ever present fluctuations and instability of 21st century work environments [9,12,13]. From the perspective of primary prevention [14-16], it is essential to act early and constantly to enhance the well-being of individuals [17-19]. The relevance of relational strengths in various contexts and especially in the work context has emerged in recent research $[1,7,20]$. To improve and manage positive relationships, the need to increase both relationships [1] and respect [21-23] have been suggested as key factors between oneself, other individuals and context demands $[7,9]$. Three pillars of respect, caring and connections with reciprocity between others and oneself are hypothesized to be fundamental for people to prosper in their personal and professional lives [8].

In this framework, the construct of positive relational management (PRM) was developed [7]. This construct is grounded in the importance of positive and healthy relationships [9] defined by respect and caring for others and the self that further recognizes both the balance in and the reciprocity of these relationships $[1,7,20]$. Thus PRM [8] goes beyond the more traditional concept of social support $[14,24]$ to include respect (my respect for others, the respect of others for me, my respect for 
myself), caring (my care for others, the care of others for me, my care for myself), and connectedness (my connectedness with family members, with friends, with significant others, and reciprocity). Relationships further include the meanings constructed and shared in organizations at the individual and social levels [10]. Thus, in this framework, sustainability and sustainable development [9] call for promoting the well-being of workers and organizations through the enhancement of positive relationships and the creation of a positive narrative in everyday organizational environments [10].

On a related topic $[15,16,25]$, emotional intelligence (EI) has emerged as a promising foundation and resource for the promotion of healthy and sustainable organizations [9-11]. In the current literature, two different views of EI are at the forefront of research [26], labelled trait EI [27,28] and ability-based EI [29]. A first group of trait models tends to describe EI as an integration of the affective dispositions of personality reflected in emotional self-perceptions $[27,30]$ and emotional self-efficacy $[28,31]$ mainly assessed through self-report measures. Among trait EI models, Bar-On model [27] presents a traditional model of trait emotional intelligence conceptualizing it as the perception of one's own emotional and social abilities that regulate an individuals relationship with themselves and with others and response to environmental demands. A more recent and comprehensive trait EI model by Petrides and Furnham $[28,31]$ refers to trait emotional self-efficacy as a constellation of self-perceptions relative to emotions related to the personality domain. This model [28,31], used in the present study, is more comprehensive, including aspects of EI such as emotion expression, emotion regulation, and self-motivation, which do not appear in the Bar-On [27] model.

In contrast, ability-based models [29] are grounded in the view that EI is an emotional ability related to understanding and managing emotions in everyday life. This group of EI models is more closely related to the cognitive abilities underlying and required in the processing and use of emotional information, and in this ability-framework, EI is detected through performance objective measures.

Emotional intelligence $[2,14]$ is associated with perceived social support, a variable that regards relational aspects. EI has also emerged in the literature $[15,16,25]$ as associated with well-being linked with positive inter- and intrapersonal relationships $[4,8]$. Good health and well-being represent one of the seventeen key sustainable development goals of the Agenda 2020-2030 of the United Nations [32] with the aim of a good quality of life for all people.

EI includes both intrapersonal awareness of oneself and of one's own emotions, managing emotions, and self-motivation and also interpersonal awareness relative to understanding the emotions of others and respecting their feelings [28,31]. These aspects of intrapersonal and interpersonal awareness can permit greater access to more in-depth understanding of oneself [12] and the positive management of our relations with others $[14,33,34]$, including integrating the self in relationships $[7,12]$. It is therefore prudent to continue our examination of the potential of the relationships between EI and such new constructs as PRM [7]. While ithas been recognized and empirically demonstrated that the major personality factors, reflected for example in the Big Five personality description, have a significant relationship with a wide range of human behaviors [35], it has also been shown that EI has quite consistently demonstrated incremental validity beyond that explained by major personality traits $[14,16,18,19,25,36,37]$. Thus, it could be expected that EI will also explain additional variance specifically in relation to PRM. Adding to the possible importance of EI is that is has been found to increase through specific training $[30,38,39]$, in contrast to personality traits that are considered essentially stable [40].

The identification and application of variables that can be increased and that are associated with relational resources in different contexts and in particular in the workplace, is important for early interventions to promote well-being from a preventive perspective focusing on individual levels contributing to organizational strengths $[7,12,14]$. It can be asserted that the creation of a positive workplace relational environment will certainly contribute to enabling workers to strengthen their personal resources that contribute to their well-being as well as contributing to the building of a healthy business organization [7] in this current complex world of work $[7,12,14]$. The search for new factors that would contribute to a positive preventive perspective [14-16] and promote relational aspects, 
teamwork and a positive relational climate in organizations [7] is a challenging issue. The positive preventive perspective [14-16] and relational theory of working [1] points out the need for individuals to enhance and manage positive relationships [7].

\section{Aim and Hypotheses}

The present study explored the relationship between trait EI and PRM, controlling for the effects of personality traits.

Specifically, the following hypotheses were formulated.

Hypotheses 1. EI will be positively associated with PRM.

Hypotheses 2. EI will contribute incremental variance beyond the big five personality traits in relation to PRM.

\section{Method}

\subsection{Participants}

One hundred seventy-six Italian workers from different public and private organizations participated in the study. Participants included 60 men (34.09\%) and 116 women (65.91\%) who ranged in age from 27 to 64 years $(M=46.36, S D=9.44)$. Participants were predominantly white Italians.

\subsection{Measures}

Big Five Questionnaire (BFQ). The Italian version of the Big Five Questionnaire BFQ [41] contains 132 items with a 5-point Likert scale response format ranging from $1=$ Absolutely false to $5=$ Absolutely true. The Cronbach alpha values reported by the authors [41] are: 0.84 for extraversion (e.g., "I am often completely absorbed in my commitments and activities"), 0.73 for agreeableness (e.g., "I hold in high regard the point of view of my colleagues"), 0.81 for conscientiousness (e.g., "I usually take care of everything in the smallest details"); 0.90 for emotional stability (e.g., "I have no trouble controlling my feelings"); and 0.75 for openness (e.g., "I like to keep myself informed of topics that are far from my areas of expertise"). The convergent validity of the BFQ factors was supported by positive correlations with the NEO Personality Inventory Revised NEO-PI-R [40] and the State-Trait Anxiety Inventory, Form X STAI [42].

Trait Emotional Intelligence Questionnaire Short Form (TEIQue-SF). The Trait Emotional Intelligence Questionnaire Short Form TEIQue-SF [43] and specifically the Italian version [44] is composed of 30 items drawn from the 153 item TEIQue. Questions are responded to on a 7-point Likert scale $(1=$ Completely disagree to $7=$ Completely agree). Examples of items are: "Expressing my emotions with words is not a problem for me" and "I often find it difficult to see things from another person's viewpoint". The Cronbach's alpha for the total EI score was 0.81 [44]. Correlations of the TEIQue-SF with the Bar-On Emotional Quotient Inventory Bar-On EQ-i [34] and the Mayer Salovey Caruso Emotional Intelligence Test MSCEIT [45] supported the construct validity of this scale.

Positive Relational Management Scale (PRMS). The Positive Relational Management Scale [7] is composed of 12 items rated on a five-point Likert scale $(1=$ strongly disagree to $5=$ strongly agree). This scale measures three dimensions: respect (e.g., "I have respect for the value and uniqueness of others"), caring (e.g., "Others often take care of me"), and connectedness (e.g., "I keep a balance in my relationships between family, friends and significant others"). The Cronbach's alpha coefficients were 0.82 for respect, 0.80 for caring, 0.81 for connectedness, and 0.85 for the total score [7]. Regarding concurrent validity, the PRMS positively and significantly correlated with the Multidimensional Scale of Perceived Social Support [24], the Satisfaction With Life Scale [46], the Meaning in Life Measure [47], and the Flourishing Scale [48]. 


\subsection{Procedure and Data Analysis}

The questionnaires were administered to small groups by a trained psychologist in accordance with Italian Privacy Law. The order of administration of the questionnaires was counterbalanced to control the effects of presentation. Descriptive statistics, Pearson's correlation coefficients and hierarchical regressions were calculated for all measures. In addition, partial correlations were reported between EI (both the total score and its four dimensions) and PRM, controlling for gender and age.

\section{Results}

Means, standard deviations, and correlations between the BFQ, TEIQue-SF, and PRM are reported in Table 1.

Table 1. Means, standard deviations, and correlations between BFQ, TEIQue-SF, PRM.

\begin{tabular}{|c|c|c|c|c|c|c|c|c|c|c|c|}
\hline Variable & 1 & 2 & 3 & 4 & 5 & 6 & 7 & 8 & 9 & 10 & 11 \\
\hline 1. BFQ Extraversion & 0.85 & & & & & & & & & & \\
\hline 2. BFQ Agreeableness & $0.28^{* *}$ & 0.78 & & & & & & & & & \\
\hline 3. BFQ Conscientiousness & 0.25 ** & $0.32 * *$ & 0.82 & & & & & & & & \\
\hline 4. BFQ Emotional stability & $0.17^{*}$ & $0.43^{* *}$ & 0.12 & 0.89 & & & & & & & \\
\hline 5. BFQ Openness & $0.44^{* *}$ & $0.51 * *$ & $0.37^{* *}$ & $0.35^{* *}$ & 0.79 & & & & & & \\
\hline 6. TEIQue Total & $0.46^{* *}$ & $0.48^{* *}$ & $0.27 * *$ & $0.58 * *$ & $0.37^{* *}$ & 0.87 & & & & & \\
\hline 7. TEIQue Well-being & $0.37^{* *}$ & $0.32 * *$ & $0.34^{* *}$ & $0.36^{* *}$ & $0.33^{* *}$ & $0.78^{* *}$ & 0.80 & & & & \\
\hline 8. TEIQue Self-control & $0.19 *$ & $0.34 * *$ & 0.10 & $0.61^{* *}$ & $0.19 *$ & $0.73^{* *}$ & $0.39^{* *}$ & 0.79 & & & \\
\hline 9. TEIQue Emotionality & $0.30^{* *}$ & $0.48^{* *}$ & 0.11 & $0.41 * *$ & $0.35^{* *}$ & $0.77^{* *}$ & $0.48^{* *}$ & $0.41 * *$ & 0.80 & & \\
\hline 10. TEIQue Sociability & 0.53 ** & $0.31 * *$ & $0.25^{* *}$ & $0.38^{* *}$ & $0.26^{* *}$ & $0.73^{* *}$ & $0.46^{* *}$ & $0.36^{* *}$ & $0.49^{* *}$ & 0.81 & \\
\hline 11. PRM & $0.35^{* *}$ & $0.39 * *$ & $0.18^{*}$ & $0.40^{* *}$ & $0.28^{* *}$ & $0.63^{* *}$ & $0.56^{* *}$ & $0.43^{* *}$ & $0.44^{* *}$ & $0.47^{* *}$ & 0.84 \\
\hline$M$ & 74.75 & 82.61 & 82.01 & 74.08 & 84.24 & 155.68 & 32.68 & 28.62 & 44.59 & 27.52 & 48.03 \\
\hline$S D$ & 8.37 & 9.03 & 8.82 & 11.22 & 8.64 & 21.85 & 6.18 & 6.23 & 6.48 & 5.58 & 5.94 \\
\hline
\end{tabular}

Note. $\mathrm{N}=176 .{ }^{* *} p<0.01 .{ }^{*} p<0.05$. PRM $=$ Positive Relational Management. Cronbach Alpha values shown on the diagonal in parenthesis.

The results of the correlational analysis confirmed that EI (both the total score and the four dimensions) was positively associated with PRM. In particular, PRM correlated $r=0.63(p<01)$ with TEIQue total; $r=0.56(p<01)$ with TEIQue well-being; $r=0.43(p<01)$ with TEIQue self-control; $r=0.44(p<01)$ with TEIQue emotionality; and $r=0.47(p<01)$ with TEIQue sociability. Partial correlations were also calculated between EI (total score and four dimensions) and PRM to determine if controlling for gender and age had an influence on the bivariate associations. The greatest difference that emerged was 0.02 , and is therefore negligible.

The results of the hierarchical regression analysis with PRM as the dependent variable and with BFQ entered at the first step, followed alternatively by the TEIQue total score (see Table 2) and then the TEIQue facets (see Table 3) are presented below.

With regard to the first model, personality traits accounted for $28 \%$ of the variance at step one. At the second step, trait EI total added $14 \%$ to the incremental variance, accounting overall for $41 \%$ of the variance.

For the second model, personality traits accounted for $28 \%$ of the variance at step one, followed by trait EI dimensions adding $16 \%$ to the incremental variance. Personality and EI accounted overall for $43 \%$ of the variance in PRM

Thus in both regression analyses, EI added at least $50 \%$ incremental variance beyond personality traits in estimating PRM. 
Table 2. Hierarchical regression. The contributions of personality traits (first step) and TEIQue total score (second step) to PRM.

\begin{tabular}{cc}
\hline & PRM \\
\hline & $\boldsymbol{\beta}$ \\
\hline Step 1 & \\
BFQ Extraversion & $0.26^{* *}$ \\
BFQ Agreeableness & $0.21^{*}$ \\
BFQ Conscientiousness & 0.03 \\
BFQ Emotional stability & $0.28^{* *}$ \\
BFQ Openness & 0.05 \\
Step 2 & \\
TEIQue Total & $0.53^{* *}$ \\
$R^{2}$ step 1 & $0.28^{* * *}$ \\
$\Delta R^{2}$ step 2 & $0.14^{* * *}$ \\
$R^{2}$ total & $0.41^{* *}$ \\
\hline Note. $N=176 .{ }^{*} p<0.05 .{ }^{* *} p<0.01 .{ }^{* * *} p<0.001$.
\end{tabular}

Table 3. Hierarchical regression. The contributions of personality traits (first step) and TEIQue dimensions (second step) to PRM.

\begin{tabular}{cc}
\hline & PRM \\
\hline & $\beta$ \\
\hline Step 1 & \\
BFQ Extraversion & $0.26^{* *}$ \\
BFQ Agreeableness & $0.21^{*}$ \\
BFQ Conscientiousness & 0.03 \\
BFQ Emotional stability & $0.28^{* *}$ \\
BFQ Openness & 0.05 \\
Step 2 & \\
TEIQue Well-being & $0.36^{* * *}$ \\
TEIQue Self-control & 0.13 \\
TEIQue Emotionality & 0.03 \\
TEIQue Sociability & $0.16^{*}$ \\
$R^{2}$ step 1 & $0.28^{* * *}$ \\
$\Delta R^{2}$ step 2 & $0.16^{* * *}$ \\
$R^{2}$ total & $0.43^{* * *}$ \\
\hline Note. $N=176 .{ }^{*} p<0.05 .{ }^{* *} p<0.01$. & ${ }^{* * *} p<0.001$.
\end{tabular}

\section{Discussion}

The present study was designed to explore the relationship between trait EI and PRM, controlling for the effects of personality traits that are known to be strong predictors of relational behaviors. EI showed incremental validity beyond that explained by personality traits in relation to positive relational management. This finding further supports the significance of EI in a description of human behaviour that reflects social-emotional well-being beyond what is attributed to major personality factors $[14,16,18,19,25,36,37]$.

The first hypothesis was confirmed. Both the intrapersonal aspects of emotional self-awareness and emotional management and also the interpersonal facets of the recognition of emotions in others and the capacity to adequately interact with others were positively related to PRM. This would follow from PRM reflecting relationality, operationally defined as respect and caring toward oneself and others, as well as the reciprocal connectedness in relationships $[7,16,19]$. It appears that because EI encompasses the perception, recognition and management of emotions, individuals higher in emotional intelligence would likely have greater positive relational management skills. These results also 
underscore the relationship between emotional intelligence and perceived social support, a relevant variable in the relationships framework $[2,14]$.

The second hypothesis was also confirmed, with both the total EI and the four facets explaining an additional 14 and 16 percent of variance respectively in PRM beyond the major personality traits. These results are also in line with the literature $[2,14]$, which showed the additional contribution of emotional intelligence with respect to personality traits in relation to perceived social support that includes relational aspects. At the level of the EI facets, well-being and sociability emerged as the two dimensions most associated with PRM, attesting to the importance of self-management when interacting and forming relationships with others. Well-being refers to the perception of having many positive personal strengths, whereas sociability relates to the effectiveness of our interaction with others. Thus, EI would appear to be a key to facilitating positive self-relational management $[12,14,33,34]$. Once again, the incremental validity that we found for EI beyond personality traits in relation to positive relational management, confirmed its potential, which has already been extensively described in the literature for other variables $[14,16,18,19,25,36,37]$.

While the current findings regarding the relationship of PRM with personality and EI are encouraging, it is necessary to stress that the sample was limited to Italian workers from the Tuscany region who are not necessarily representative of all Italian workers. Future research should also extend the study of the relationship between these variables to workers with specific occupations from different organizations and from different geographical areas in Italy and certainly beyond in other countries. It will be also important to confirm these results in other studies and in the broader organizational and international contexts. It will be also useful in future research to investigate EI and PRM in relation to other promising constructs for healthy organizations in a prevention perspective that would include human capital sustainability leadership [49] among leadership styles, workplace relational civility [3], resiliency [50], and work related eustress and distress [51].

Notwithstanding these limitations, if the results of the present study are confirmed in future research, there are potential practical applications. EI is an individual differences factor that can be developed and increased $[38,39,52,53]$. Thus interventions could be introduced to enhance trait EI that in turn may contribute further to increasing positive relational management attitudes and skills $[16,18,19,54-56]$.

\section{Conclusions}

These present results add support to the hypothesis that trait EI may be regarded as a positive individual differences variable that is further related to enhancing and managing positive relationships, improving respective and relationality, and promoting well-being in the workplace leading to healthy and sustainable organizations and work environments. The focus on trait EI and its relations with PRM opens new pathways to building individual and group relational strengths [12,16]. EI may represent a promising resource in tandem with PRM in contributing to the goal of good health and well-being for all people [32].

Author Contributions: Conceptualization, A.D.F. and D.H.S.; Data curation, A.D.F and D.H.S.; Investigation, A.D.F.; Methodology, A.D.F. and D.H.S.; Supervision, D.H.S.; Writing-original draft, A.D.F. and D.H.S.; Writing-review \& editing, A.D.F. and D.H.S.

Funding: This research received no external funding.

Conflicts of Interest: The authors declare no conflict of interest.

\section{References}

1. Blustein, D.L. A relational theory of working. J. Voc. Behav. 2011, 79, 1-17. [CrossRef]

2. Austin, E.J.; Saklofske, D.H.; Egan, V. Personality, well-being and health correlates of trait emotional intelligence. Pers. Individ. Difer. 2005, 38, 547-558. [CrossRef] 
3. Di Fabio, A.; Gori, A. Assessing Workplace Relational Civility (WRC) with a new multidimensional "mirror" measure. Front. Psychol. 2016, 7, 890. [CrossRef] [PubMed]

4. Gallagher, E.N.; Vella-Brodrick, D.A. Social support and emotional intelligence as predictors of subjective well-being. Pers. Individ. Difer. 2008, 44, 1551-1561. [CrossRef]

5. Suldo, S.M.; Friedrich, A.A.; White, T.; Farmer, J.; Minch, D.; Michalowski, J. Teacher support and adolescents' subjective well-being: A mixed-methods investigation. Sch. Psychol. Rev. 2009, 38, 67-85.

6. Ferguson, S.J.; Goodwin, A.D. Optimism and well-being in older adults: The mediating role of social support and perceived control. Int. J. Aging Hum. Dev. 2010, 71, 43-68. [CrossRef] [PubMed]

7. Di Fabio, A. Positive Relational Management for healthy organizations: Psychometric properties of a new scale for prevention for workers. Front. Psychol. 2016, 7, 1523. [CrossRef]

8. Snyder, C.R.; Lopez, S.; Teramoto Pedrotti, J. Wisdom and courage: Two universal virtues, In Positive Psychology: The Scientific and Practical Explorations of Human Strengths; Snyder, C.R., Lopez, S., Pedrotti, J.T., Eds.; Sage: London, UK, 2014; pp. 205-242, ISBN 1452276439.

9. Di Fabio, A. Positive Healthy Organizations: Promoting well-being, meaningfulness, and sustainability in organizations. Front. Psychol. 2017, 8, 1938. [CrossRef]

10. Di Fabio, A. The psychology of sustainability and sustainable development for well-being in organizations. Front. Psychol. 2017, 8, 1534. [CrossRef]

11. Peiró, J.M.; Ayala, Y.; Tordera, N.; Lorente, L.; Rodríguez, I. Bienestar sostenible en el trabajo: Revisión y reformulación [Sustainable wellness at work: Review and reformulation]. Papeles del Psicólogo 2014, 35, 5-14.

12. Di Fabio, A.; Kenny, E.M. From decent work to decent lives: Positive Self and Relational Management (PS\&RM) in the twenty-first century. Front. Psychol. 2016, 7, 361. [CrossRef] [PubMed]

13. Peiró, J.M.; Rodríguez, I. Work stress, leadership and organizational health. Papeles del Psicólogo 2008, 29, 68-82.

14. Di Fabio, A.; Kenny, M.E. Emotional intelligence and perceived social support among Italian high school students. J. Career Dev. 2012, 39, 461-475. [CrossRef]

15. Di Fabio, A.; Kenny, M.E. The contributions of emotional intelligence and social support for adaptive career progress among Italian youth. J. Career Dev. 2015, 42, 48-49. [CrossRef]

16. Di Fabio, A.; Kenny, M.E. Promoting well-being: The contribution of emotional intelligence. Front. Psychol. 2016, 7, 1182. [CrossRef] [PubMed]

17. Di Fabio, A.; Palazzeschi, L. Hedonic and eudaimonic well-being: The role of resilience beyond fluid intelligence and personality traits. Front. Psychol. Sect. Dev. Psychol. 2015, 6, 1367. [CrossRef] [PubMed]

18. Di Fabio, A.; Saklofske, D.H. Comparing ability and self-report trait emotional intelligence, fluid intelligence, and personality traits in career decision. Pers. Individ. Difer. 2014, 64, 174-178. [CrossRef]

19. Di Fabio, A.; Saklofske, D.H. Promoting individual resources: The challenge of trait emotional intelligence. Pers. Individ. Difer. 2014, 65, 19-23. [CrossRef]

20. Blustein, D.L. The Psychology of Working: A New Perspective for Counseling, Career Development, and PublicPolicy; Lawrence Erlbaum Associates: Mahwah, NJ, USA, 2006; ISBN 978-0805858792.

21. Di Fabio, A. The effectiveness of the career construction interview from the perspective of life designing. S. Afr. J. Higher Educ. 2012, 26, 717-728.

22. Di Fabio, A. Positive Relational Management Scale per rilevare positività e complessità [Positive Relational Management Scale to detect positivity and complexity]. Couns. G. Ital. Ric. Appl. 2015, 8.

23. Maree, J.G. Editorial. Promoting children's rights: Rekindling respectivity. S. Afr. J. Psychol. 2012, 42, $295-300$. [CrossRef]

24. Zimet, G.D.; Dahlem, N.W.; Zimet, S.G.; Farley, G.K. The multidimensional scale of perceived social support. J. Pers. Assess. 1988, 52, 30-41. [CrossRef]

25. Di Fabio, A.; Palazzeschi, L. Organizational justice: Personality traits or emotional intelligence? An empirical study in an Italian hospital context. J. Employ. Couns. 2012, 49, 31-42. [CrossRef]

26. Stough, C.; Saklofske, D.; Parker, J. Assessing Emotional Intelligence: Theory, Research, and Applications; Springer: New York, NY, USA, 2009; ISBN 038788369X.

27. Bar-On, R. The Emotional Intelligence Inventory (EQ-i): Technical Manual; Multi-Health Systems: Toronto, ON, Canada, 1997; ISBN 978-88-7466-497-9.

28. Petrides, K.V.; Furnham, A. Trait emotional intelligence: Psychometric investigation with reference to established trait taxonomies. Eur. J. Per. 2001, 15, 425-428. [CrossRef] 
29. Mayer, J.D.; Salovey, P. What is emotional intelligence? In Emotional Development and Emotional Intelligence: Educational Implications; Salovey, P., Sluyter, D., Eds.; Basic Books: New York, NY, USA, 1997; pp. 3-31, ISBN 0465095879.

30. Siegling, A.B.; Vesely, A.K.; Petrides, K.V.; Saklofske, D.H. Incremental Validity of the Trait Emotional Intelligence Questionnaire-Short Form (TEIQue-SF). J. Pers. Assess. 2015, 97, 525-535. [CrossRef] [PubMed]

31. Petrides, K.V.; Furnham, A. On the dimensional structure of emotional intelligence. Pers. Individ. Difer. 2000, 29, 313-320. [CrossRef]

32. United Nations. About the Sustainable Development Goals. 2018. Available online: Https://www.un.org/ sustainabledevelopment/sustainable-development-goals / (accessed on 4 September 2018).

33. Mavroveli, S.; Petrides, K.V.; Rieffe, C.; Bakker, F. Trait emotional intelligence, psychological well-being and peer-rated social competence in adolescence. Br. J. Dev. Psychol. 2007, 25, 263-275. [CrossRef]

34. Petrides, K.V.; Sangareau, Y.; Furnham, A.; Frederickson, N. Trait emotional intelligence and children's peer relations at school. Soc. Dev. 2006, 15, 537-547. [CrossRef]

35. Keefer, K.V.; Parker, J.D.A.; Saklofske, D.H. Emotional intelligence, stress, and health: When the going gets tough, the tough turn to emotions. In An Introduction to Emotional Intelligence; Poole, L.D., Qualter, P., Eds.; Wiley, The British Psychological Society: Hoboken, NJ, USA, 2018; pp. 161-183, ISBN 978-1-119-11442-0.

36. Di Fabio, A. Beyond fluid intelligence and personality traits in social support: The role of ability based emotional intelligence. Front. Psychol. Sect. Educ. Psychol. 2015, 6, 395. [CrossRef]

37. Di Fabio, A.; Saklofske, D.H. The contributions of personality and emotional intelligence to resiliency. Person. Individ. Differ. 2018, 123, 140-144. [CrossRef]

38. Di Fabio, A.; Kenny, M.E. Promoting emotional intelligence and career decision making among Italian high school students. J. Career Assess. 2011, 19, 21-34. [CrossRef]

39. Vesely, A.K.; Saklofske, D.H.; Nordstokke, D. EI training and pre-service teacher wellbeing. Pers. Individ. Difer. 2014, 65, 81-85. [CrossRef]

40. Costa, P.T.; McCrae, R.R. NEO PI-R Professional Manual; Psychological Assessment Resources: Odessa, FL, USA, 1992; ISBN 9997924452.

41. Caprara, G.V.; Barbaranelli, C.; Borgogni, L. BFQ: Big Five Questionnaire, 2nd ed.; Giunti O.S.: Firenze, Italy, 1993; ISBN 8809400674.

42. Spielberger, C.D.; Gorsuch, R.L.; Lushene, R.E. State-Trait Anxiety Inventory; Consulting Psychology Press: Palo Alto, CA, USA, 1968; ISBN 8809400933.

43. Petrides, K.V.; Furnham, A. Technical Manual of the Trait Emotional Intelligence Questionnaire (TEIQue); Institute of Education, University of London: London, UK, 2006.

44. Di Fabio, A.; Palazzeschi, L. Proprietà psicometriche del Trait Emotional Intelligence Questionnaire Short Form (TEIQue-SF) nel contesto italiano [Psychometric properties of the Trait Emotional Intelligence Questionnaire Short Form (TEIQue-SF) in the Italian context]. Counseling. Couns. G. Ital. Ric. Appl. 2011, 4, 327-336.

45. Caruso, D.R.; Mayer, J.D.; Salovey, P. Relation of an ability measure of emotional intelligence to personality. J. Pers. Assess. 2002, 79, 306-320. [CrossRef] [PubMed]

46. Diener, E.D.; Emmons, R.A.; Larsen, R.J.; Griffin, S. The satisfaction with life scale. J. Pers. Assess 1985, 49, 71-75. [CrossRef] [PubMed]

47. Morgan, J.; Farsides, T. Measuring meaning in life. J. Happiness Stud. 2009, 10, 197-214. [CrossRef]

48. Diener, E.; Wirtz, D.; Tov, W.; Kim-Prieto, C.; Choi, D.W.; Oishi, S.; Biswas-Diener, R. New well-being measures: Short scales to assess flourishing and positive and negative feelings. Soc. Indic. Res. 2010, 97, 143-156. [CrossRef]

49. Di Fabio, A.; Peiró, J.M. Human Capital Sustainability Leadership to promote sustainable development and healthy organizations: A new scale. Sustainability 2018, 10, 2413. [CrossRef]

50. Wilson, C.A.; Plouffe, R.A.; Saklofske, D.H.; Di Fabio, A.; Prince-Embury, S.; Babcock, S.E. Resiliency across cultures: A validation of the Resiliency Scale for Young Adults. J. Psychoeduc. Assess. 2017. [CrossRef]

51. Di Fabio, A.; Peiró, J.M.; Rodríguez, I.; Kozusznik, M.W. The Valencia Eustress-Distress Appraisal Scale (VEDAS): Validation of the Italian version. Sustainability 2018, 10, 3903. [CrossRef]

52. Kotsou, I.; Nelis, D.; Grégoire, J.; Mikolajczak, M. Emotional plasticity: Conditions and effects of improving emotional competence in adulthood. J. Appl. Psychol. 2011, 96, 827. [CrossRef] [PubMed]

53. Nelis, D.; Quoidbach, J.; Mikolajczak, M.; Hansenne, M. Increasing emotional intelligence:(How) is it possible? Pers. Individ. Difer. 2009, 47, 36-41. [CrossRef] 
54. Hage, S.M.; Romano, J.L.; Conyne, R.K.; Kenny, M.; Matthews, C.; Schwartz, J.P.; Waldo, M. Best practice guidelines on prevention practice, research, training, and social advocacy for psychologists. Couns. Psychol. 2007, 35, 493-566. [CrossRef]

55. Israelashvili, M.; Romano, J.L. The Cambridge Handbook of International Prevention Science; Cambridge University Press: Cambridge, UK, 2016; pp. 233-254, ISBN 9781107087972.

56. Kenny, M.E.; Hage, S.M. The next frontier: Prevention as an instrument of social justice. J. Prim. Prev. 2009, 30, 1-10. [CrossRef] [PubMed]

(C) 2019 by the authors. Licensee MDPI, Basel, Switzerland. This article is an open access article distributed under the terms and conditions of the Creative Commons Attribution (CC BY) license (http://creativecommons.org/licenses/by/4.0/). 